\title{
What Role Should Government Regulation Play in Ecological Restoration? Ongoing Debate in São Paulo State, Brazil
}

\author{
James Aronson, ${ }^{1,2,3 *}$ Pedro H. S. Brancalion, ${ }^{4 *}$ Giselda Durigan, ${ }^{5 *}$ Ricardo R. Rodrigues, ${ }^{6}$ Vera \\ L. Engel, ${ }^{7}$ Marcelo Tabarelli, ${ }^{8}$ José M. D. Torezan, ${ }^{9}$ Sergius Gandolfi, ${ }^{6}$ Antônio C. G. de Melo, ${ }^{5}$ \\ Paulo Y. Kageyama, ${ }^{4}$ Márcia C. M. Marques, ${ }^{10}$ André G. Nave, ${ }^{6}$ Sebastião V. Martins, ${ }^{11}$ Flávio \\ B. Gandara, ${ }^{6}$ Ademir Reis, ${ }^{12}$ Luiz M. Barbosa, ${ }^{13}$ and Fabio R. Scarano ${ }^{14,15}$
}

\begin{abstract}
Around the world, there is growing desire and momentum for ecological restoration to happen faster, with better quality, and in more extensive areas. The question we ask is how can laws and governmental regulations best contribute to effective, successful, and broad-scale restoration? In the state of São Paulo, Brazil, there is a legal instrument (SMA 08-2008) whose aim is to increase the effectiveness of tropical forest restoration projects in particular. It establishes, among other things, requirements regarding the minimum number of native tree species to be reached within a given period of time in restoration projects and the precise proportion of functional groups or threatened species to be included when reforestation with native species is used as a restoration technique. There are, however, two differing perspectives among Brazilian restoration ecologists
\end{abstract}

on the appropriateness of such detailed legal rules. For some, the rules help increase the chances that mandatory projects of ecological restoration will succeed. For the other group, there is no single way to achieve effective ecosystem restoration, and the existing science and know-how are far from sufficient to establish standardized technical and methodological norms or to justify that such norms be imposed. Both points of view are discussed here, aiming to help those developing new legislation and improving existing laws about ecological restoration. The precedents established in São Paulo, and at the federal level in Brazil, and the ongoing debate about those laws are worth considering and possibly applying elsewhere.

Key words: decision-making processes, ecosystem restoration, environmental policy, legal instruments, regulation.
${ }^{1}$ Centre d'Ecologie Fonctionnelle et Evolutive (CNRS-UMR 5175), 1919, Route de Mende, 34293 Montpellier, France

2 Missouri Botanical Garden, St. Louis, MO 63110, U.S.A

3 Address correspondence to J. Aronson, email james.aronson@ cefe.cnrs.fr

${ }^{4}$ Department of Forest Sciences, University of São Paulo, ESALQ, Av. Pádua Dias 11, 13.418-900, Piracicaba, SP, Brazil

${ }^{5}$ Forestry Institute of the State of São Paulo, Assis State Forest, PO Box 104 19802-970, Assis, SP, Brazil

${ }^{6}$ Department of Biological Sciences, University of São Paulo, ESALQ, Av. Pádua Dias 11, 13.418-900, Piracicaba, SP, Brazil

${ }^{7}$ Faculty of Agronomic Sciences, Department of Natural Resources, São Paulo State University-UNESP, PO Box 237, 18603-970 Botucatu, SP, Brazil

${ }^{8}$ Department of Botany, Federal University of Pernambuco, Av. Moraes Rego s/n, Cidade Universitária, 50670-901 Recife, PE, Brazil

${ }^{9}$ Centre of Biological Sciences, State University of Londrina, PO Box 6001, 86.051-990 Londrina, PR, Brazil

${ }^{10}$ Laboratório de Ecologia Vegetal, Universidade Federal do Paraná, Curitiba, Brazil

${ }^{11}$ Department of Forestry Engineering, Federal University of Viçosa, PO Box 218, 36570-000 Viçosa, MG, Brazil

12 Department of Botany, Federal University of Santa Catarina, 88040-900, Trinidade, Florianópolis, SC, Brazil

${ }^{13}$ Institute of Botany-State of São Paulo, Av. Miguel Stéfano, 3687, 04301-902 São Paulo, SP, Brazil

${ }^{14}$ Conservation International, Rua Buenos Aires 68, 26 andar, cep 20070-022, Rio de Janeiro, RJ, Brazil

\section{Introduction}

Large-scale ecological restoration efforts in tropical developing countries such as Brazil, and elsewhere, entail social, political, economic, judicial, scientific, and technological aspects that should all be addressed. This is true in many cases, for instance, when the primary goal is to allow wild species and their communities to persist and evolve as communities within human-dominated agromosaics and semi-urbanized landscapes (Tabarelli et al. 2010). Especially in tropical developing countries, where two-thirds of global biodiversity hotspots are located, restoration efforts are required to mitigate the increasingly rapid and alarming erosion of biodiversity (Mittermeier et al. 2004) driven by deforestation and degradation of tropical

\footnotetext{
15 Universidade Federal do Rio de Janeiro, CCS, IB, Depto de Ecologia, Cx Postal 68020, cep 21041-970, Rio de Janeiro, RJ, Brazil

${ }^{*}$ The first three authors are listed in alphabetical order; they contributed equally to this paper.
}

(c) 2011 Society for Ecological Restoration International doi: 10.1111/j.1526-100X.2011.00815.x 
forests (Chazdon 2008) among other land use changes and anthropogenic climate change. Such a holistic approach is also required when restoration initiatives aim primarily to enhance better practices in the context of ongoing economic activities (Rodrigues et al. 2010) so as to augment and retain the range of ecosystem services for society, while also enhancing biodiversity protection and preservation (Rey Benayas et al. 2009; Calmon et al. 2011; Bullock et al. in press). Needless to say, it also holds true for programs aiming to incorporate restoration as part of the planning strategy for societies seeking make a lasting transition toward sustainability (Clewell \& Aronson 2007; Neßhöver et al. 2011).

Notably, the recent ratification of the REDD/REDD+ (reduced deforestation, reduced degradation, enhancement of forest carbon stocks, sustainable management of forest, and conservation of forest carbon stocks) protocol of the United Nations Framework Convention on Climate Change may stimulate public policy for large-scale investments, both at national and subnational levels. The desired result is reduced degradation, sustainable management of forests of various kinds, and "forest enhancement"-which explicitly includes forest restoration (Herold \& Skutsch 2011).

However, despite the rapidly increasing demand for tropical forest restoration, there are few large-scale initiatives to date, and even fewer that are set up as controlled experiments. This plus the long-term nature of the regeneration processes-even in the tropics-limits our understanding of the biological, technological, and social prerequisites for implementing effective forest restoration across a range of settings. Moreover, as demand increases, ecological restoration will be required to be more holistic and cost-effective (Birch et al. 2010). In this context, public legislation is a potential - and potentially critical - ally to guarantee that best practices, i.e. practices based on existing science and know-how, are incorporated within restoration projects and programs. However, in Brazil-the topic of this paper - neither the technical content nor the scope of such regulations is readily agreed upon among practitioners and researchers.

In synthesis, legal regulations concerning restoration raise opportunities, but may also create confusion and conflict among stakeholders (see Alexander et al. in press). As noted by Ruiz-Jaen and Aide (2005), existing laws usually do not include requirements for comparison with reference sites or other methods of evaluating restoration success that many restoration ecologists consider fundamental. Yet, if laws do not require replications, controls, reference sites, and so on, it is unlikely that such procedures will be incorporated into restoration projects, especially mandatory projects on private lands. This is due very simply to the increased establishment and monitoring costs such procedures entail. However, when restoration is considered to be a key element of a survival and sustainability strategy for society as a whole and, as a result, restoration programs override private land rights, it is necessary to specify precisely how far the law should go to improve and guide restoration practice on the basis of current scientific knowledge. In this context, laws and regulations should provide (1) guidelines to practitioners and managers; (2) incentives and disincentives to those whose activities cause environmental damage; (3) fiscal penalties for those who do not pay their "natural capital debt" for the damage they cause; (4) stimulus for restoring strategic priority areas at the regional scale to increase connectivity; and (5) facilitation and support for both public and private agencies and enterprises necessary for the advancement and implementation of restoration best practice, knowledge, and ongoing scientific research.

In the Brazilian state of São Paulo, a recent resolution on forest restoration (see below) is expected to guarantee that stakeholders-many of whom are unfamiliar with the basics of ecosystem restoration-recognize the need for, and adopt better practices (Brancalion et al. 2010). However, some restoration ecologists disagree with particular details of the legislation, because technology-related and ecology-based procedures required to achieve effective forest restoration are still under scientific investigation, and the role of specific site context is a complex issue. Thus, existing science may not yet be sufficient to standardize or mainstream technical and methodological norms (Durigan et al. 2010).

Here, we review the main aspects of current legal instruments devoted to ecological restoration and address São Paulo state legislation as a case study, with its potential benefits and coverage (Brancalion et al. 2010) and also its limitations (Durigan et al. 2010) and controversial aspects (Aronson 2010). We highlight some emerging lessons from the São Paulo debate and its practical implications for adopting legislation as a tool to guarantee that restoration initiatives achieve current social, scientific, and technical expectations.

\section{The Role of Legal Instruments in Ecological Restoration}

Both financial and nonfinancial drivers for ecological restoration exist (Clewell \& Aronson 2006; chapters 32 and 33 in Aronson et al. 2007; Birch et al. 2010; Neßhöver et al. 2011), and legal instruments already play a part in inducing restoration, at least in some countries. For instance, nearly $60 \%$ of the 68 papers reviewed by Ruiz-Jaen and Aide (2005) to assess how restoration success has been measured-all of them published in Restoration Ecology - were carried out to comply with laws (e.g. the Clean Water Act in the U.S.A., the National Environment Protection Measures Act in Australia, and stringent laws governing closure requirements for extraction companies - mining, logging, etc., in Canada, and elsewhere.

In Brazil, restoration efforts are required to comply with environmental laws (Rodrigues et al. 2011). Although legal enforcement can help in most situations, it can also create obstacles. National rules and regulations, in theory, must be socially fair, knowledge-based, applicable to well-defined areas or situations, and well communicated to stakeholders and the public. They should be accompanied by fiscal incentives to encourage voluntary investments and not just penalties 
for landowners and companies that fail to comply (Durigan et al. 2010).

All too often, restoration laws (e.g. in the U.S.A.) allow compensation or mere cleaning-up, instead of demanding and facilitating effective, feasible, and knowledge-based in situ restoration or at least rehabilitation (Clewell \& Aronson 2006, 2007). In cases of conflicting interests, governments should decide who will pay for restoration and who should benefit from the enhanced ecosystem services that restoration initiatives are expected to provide. In addition, if restoration ex situ is used as a means of compensating for environmental damage and loss of natural capital (i.e. as mitigation for damages done to the environment), government agencies and courts should decide on clear standards to be met in order for such an initiative to be accepted as adequate compensation.

As far as we know, the use of detailed legislation to guide restoration practices as adopted in São Paulo state has no parallel elsewhere. In other countries where policies and laws regarding restoration exist, they are intended to set general targets and allocate technical support and government funding or subsidies to facilitate action - under the aegis of supportive public policies.

Brazil is one of a handful of developing countries - along with South Africa, Namibia, Ecuador, Costa Rica, Vietnam, and India-where public policy and detailed legislation on restoration exist or are being developed to promote, reward, or enforce restoration of degraded ecosystems. In South Africa, for example, the task of conserving and restoring biodiversity on private land involves negotiation, because the government recognizes that the costs are individual and benefits are collective. Therefore, government policy in that country is conceived to develop a range of benefits for the restoration practitioner, including tax deductions for all costs of management and, in some cases, on land value (T. Cumming 2010, South African National Biodiversity Institute, personal communication). In contrast, under Japan's Forestry Law, landowners are compensated financially if their lands are designated as forests requiring protection and must be removed from production. In addition, costs of restoration and rehabilitation are partially covered by the public sector (http://law.e-gov.go.jp/cgi-bin/idxsearch.cgi). Ecological Restoration programs in China that began in 1990 are implemented with strong government support (Yin \& Yin 2009). However, none of the countries cited here attempts to include techniques, guidelines, and minimum standards in the legislative regulations concerning restoration. Brazil seems to be unique in this regard.

\section{São Paulo Case Study}

In the state of São Paulo, an intense effort to legislate restoration practice began in 2000. The legislation was stimulated by a history of failures to mitigate environmental damages, mainly because of low resilience and very sparse forest cover at the landscape scale. An extensive evaluation of restoration plantings (Barbosa et al. 2003) indicated that (1) few plantations were successful; (2) most existing plantations exhibited low species diversity; and (3) a small group of species, often well-known pioneers, was planted in large proportions on all sites. To aggravate the problem, the environmental secretariat was only allowed 2 years after project start-up to consider a specific area as "restored" or not. This was clearly insufficient to verify whether a project would be successful, i.e. self-perpetuating, in the mid- or long term.

To identify the most effective known restoration practices, the São Paulo State Environmental Secretariat (hereafter SMA), through the São Paulo State Institute of Botany, organized several public meetings over the past 10 years. Members of the scientific community and some important stakeholders - although practitioners and landowners were insufficiently represented - of forest restoration of São Paulo were invited and participated to help develop recommendations, based on previous experience and current scientific knowledge, and to create and improve a state resolution for ecological restoration. Hence, the resolution presented below was drafted democratically by some important stakeholders and restorationists working with politicians, rather than by policy makers working alone, in a top-down manner. The first version of the SMA resolution was drafted in 2001, the second in 2003, the third in 2007, and the fourth in 2008 (see translation of the latest version posted as Appendix S1); a fifth version of this legislation is currently under debate and is to be issued in late 2011.

Briefly, the SMA 08/2008 legislation aims to adopt procedures to achieve more effective forest restoration. Since 2003 , but more clearly still after 2007, its compliance is mandatory only for restoration initiatives planned to compensate for, and mitigate against, environmental damage resulting from economic activities, violations of environmental laws, or for projects supported by public resources. However, over the past decade, the legislation was also frequently - and improperly-applied to those landowners who were not obliged under law, but went ahead anyway with voluntary restoration initiatives on their lands. The three essential provisions of the proposed legislation are as follows:

(1) Carry out a diagnostic procedure to identify and remove anthropogenic disturbances in the areas to be restored, define restoration priorities, characterize and ameliorate soils as part of restoration efforts, control invasive species, and select the most appropriate restoration practices for each context or situation where degradation has taken place (articles $3^{\circ}, 5^{\circ}, 9^{\circ}, 10^{\circ}$, and $11^{\circ}$ ).

(2) Reach a minimum of 80 native woody plant species within a given period of time, in all restoration projects, including assisted regeneration. This applies only to the natural high-diversity seasonally dry forests, Atlantic rainforests, and Savanna woodlands, for which much experience in restoration exists. In contrast, for lower diversity swamp forests, restinga, and dry deciduous forests, for which little practical restoration know-how exists, no legal minimum species richness has yet been established. In addition, for reforestation projects, in particular, several other requirements were specified. First, minimum percentages of animal-dispersed (20\%) and endangered species $(5 \%)$ 
are required, and second, a maximum of $60 \%$ of species and individuals belonging to the same ecological group (pioneer and non-pioneer) can be used. Finally, no more than $10 \%$ of the species can be represented by less than 12 individuals per project (article $6^{\circ}$ ).

(3) The São Paulo State Institute of Botany shall suggest priority topics for research, training, and outreach programs to enhance the effectiveness of ecological restoration (article 13), as well as provide an updated list of native species recommended for use in each region of the State (article $\left.8^{\circ}\right)$.

Notably, the very recent National Resolution for Restoration (Resolução CONAMA 429 of 28 February 2011; see Appendix S2) establishes simple and general rules for the whole country, without going into details about specific techniques. However, this new federal resolution will not necessarily affect the above-mentioned, much more detailed resolution SMA 08/2008 in São Paulo State. In Brazil, as in many countries, federal rules establish a baseline, but individual States can go beyond the federal rules on certain points.

\section{Ongoing Debate}

In our collective opinion, it is legitimate that society requires minimum quality standards to be reached by restoration projects initiated to compensate for environmental damage (e.g. removal of native vegetation and loss of ecosystem services) or those supported by public resources. However, Durigan et al. (2010) - and roughly half the authors of the present article-consider that while the overarching goals, and processes, of ecological restoration should be written into law, the specific techniques to be applied to reach such goals should not. Although Brancalion et al. (2010) agree that the main focus should be the results, they argue that laws and regulations on "how to restore" can encourage effective restoration without specifying performance standards. In this section, we discuss both points of view.

The most frequent criticism of the São Paulo legislation refers to a minimum of 80 native tree and shrub species that are required for all restoration projects to be legally acceptable in the high-diversity forest types mentioned above. This article of the SMA 08/2008 resolution intends that "restored" forests should approximate, insofar as possible, the levels of plant species richness (particularly tree and shrub species) observed in the reference ecosystems for those forest types. For Brancalion et al. (2010), this requirement is in harmony with the SER Primer on Ecological Restoration (SER 2004), which urges restorationists to assist the regeneration of degraded or damaged ecosystems to the point where they harbor a representative portion of its typical biodiversity. In addition, these authors have suggested including other life forms, rather than just trees and shrubs, to promote the recovery of overall plant community composition. For Durigan et al. (2010), however, imposing a minimum number of 80 woody plant species offer no guarantee that restored forest will achieve self-sustainability or biological viability. For these authors, successful restoration can be reached in very different ways and failure (e.g. high mortality among desired species and recolonization by African grasses) is common even if the rules of resolution are strictly followed. In addition, Durigan et al. (2010) agree with Ehrenfeld (2000) and Hobbs (2007), who argue that in many situations, such as those in highly altered landscapes, the goal of restoration cannot be a historically based reference ecosystem, as that appears impossible to reach. In reply, Brancalion et al. (2010) argue that in such cases, the term "restoration" no longer applies and some other term should be employed.

In SMA 08/2008, in fact, the number of minimum required native woody species was defined on the advice of the main forest nurseries of the State, which indicated that 80 species was an attainable goal. Furthermore, since SMA legislation was launched in 2001 in São Paulo State, there has been a clear increase in Atlantic Forest restoration projects including more than 80 tree and shrub species (Brancalion et al. 2010). In contrast to those initiatives adopting few species there is no evidence so far that high-diversity reforestations are collapsing or have failed to attain a self-perpetuating stage within 10-20 years post plantation (Castanho 2009; Rodrigues et al. 2011). Although having high diversity of woody species is a great step toward effective tropical forest restoration (Brancalion et al. 2010), only continued monitoring will determine whether these high-diversity forests are indeed on the path to becoming fully restored. Durigan et al. (2010) argue that selfsustainability of these reforestation projects was not scientifically demonstrated, because 20 years of secondary succession does not guarantee long-term success or self-sustainability. Furthermore, these authors note that, although common, failures are for the most part not publicized or even documented. Monitoring good and bad restoration initiatives should indicate which are the conditioning factors explaining restoration success. According to Durigan et al. (2010), the SMA regulations are not adequately supported by sufficient knowledge with respect to ecological processes such as assembly rules and ecological succession in tropical forests to mandate universal standards. Furthermore, the technicians who install projects, and those public servants who license and monitor them, generally do not have the knowledge necessary to implement or enforce these laws accurately.

In addition to inadequate scientific and silvicultural training and staff support, Durigan et al. (2010) consider that the SMA legislation inhibits restoration efforts by increasing their costs due to the elevated number of species demanded and because seeds and seedlings of 80 or more native tree species are often lacking locally. Almost all ecological restoration in Brazil has been conducted on privately owned lands (Rodrigues et al. 2010), and the cost to be paid for tropical forest restoration is already quite high. For example, restoration of Brazilian Atlantic Forest via initial reforestation with native species typically costs circa US\$ 5,000/ha, according to Oliveira et al. (2008). That is equivalent to the estimated revenues of circa 20 years of conventional agriculture, i.e. US\$ 250/ha/year, or much longer for cattle raising (Instituto de Economia Agrícola of São Paulo State, unpublished data). 
In reply, the group of Brazilian restoration ecologists supporting current legislation (Brancalion et al. 2010) point out that from 2003 to 2010, seedling production of shrubs and tree species in São Paulo state increased from 13 million to 42 million per year, and the average number of native woody plant species produced in commercial nurseries jumped from 30 to over 80 (Barbosa et al. 2009; Martins 2011), with no increase in average seedling price. These figures reflect a steady increase in the number and magnitude of restoration initiatives, as well as the consolidation of a production chain based on reforestation with native species. However, they acknowledge that it is not possible to affirm that such an increment resulted directly from the SMA 08/2008 resolution, as over the past decade the obligation to restore forests has been extended throughout Brazil since enactment of the country's first Environmental Crimes Law in 1998. Before 1998, most environment damages were considered as misdemeanors, and guilty parties were liable to a fine or administrative procedures at most. Under the new law, however, these damages are considered under the penal code, and guilty parties are subject not only to penalties but also to arrest and imprisonment, or at least to be obliged to restore or compensate in some active way.

Yet another important matter for discussion is when exactly the minimum number of woody species required by the existing law for all restoration projects should be verified and demonstrated. No specific rules are imposed because the project manager is required to specify the time frame for compliance with this requirement, and the environmental secretariat evaluates the feasibility of the suggested timeline.

Finally, no firm consensus is present as yet on the three points under debate, namely: (1) should legal instruments include goals such as minimum number of species and functional composition? (2) should legislation on this topic be delayed until adequate scientific knowledge is available? and (3) should legislation ever address these topics? Regardless of the debate, there is a clear consensus that much more applied research - and development - is needed to support public policies on ecological restoration. Both groups agree that the most favorable situation would be to introduce into legislation a set of general goals to be reached in the course of the restoration process. But in order to prescribe specific restoration methods considered acceptable by scientists and landowners, additional efforts in research and negotiation are required. For Brancalion et al. (2010) methods or basic standards should be in the law. For Durigan et al. (2010) they should just be provided as technical assistance. A discussion for a new text of the State legislation is currently underway, and some of these topics are being considered.

\section{Lessons Learned and the Way Forward}

To scale up ecological restoration, as well as increase its effectiveness, there is clear and urgent need-in Brazil and everywhere else-for education, capacity building, and outreach among landowners, technical practitioners, entrepreneurs, and native plant nursery owners, as well as policy makers and personnel they designate to evaluate restoration projects. In addition, economic incentives should be studied by lawmakers, including tax benefits, direct subsidies, certification of products brought to market, and more (Aronson et al. 2007).

Modifications to existing legislation are also needed to take into account regional variations in the availability of plant material, landholding size and tenure, and the results of projects undertaken to date. With this approach, legislation is more likely to help improve the effectiveness of ecosystem restoration initiatives and convince stakeholders and society as a whole to support investments in restoration. The São Paulo State Environmental Secretariat recently launched a new policy statement on Climate Change, which goes in that direction. This law introduces payments and other economic incentives for conserved and restored forests to meet the high cost of ecological restoration and convince more landowners to restore native forests on their lands (see translated copy of the "Forest Remnants Program" of this decree provided as Appendix S3).

\section{Implications for Practice (in the Field and Legislature)}

- Public regulation is required as far as it can effectively improve the quality, and increase the scale, of restoration projects and programs, while also respecting social justice and landowners' property rights.

- Public regulation is necessary to clearly state in which situations restoration is mandatory and how far should it go in terms of standards and goals.

- In the case of volunteer initiatives, legislation should only provide mechanisms to allocate technical support and government funding or subsidies to facilitate action.

- Legal instruments should be created or reinforced to protect societal interests linked to public investment in ecological restoration and to ensure compensation for environmental damage, through restoration efforts, and not just fines paid to a court.

- Guidelines and legislation should be sufficiently flexible to allow for regional variations in best practice so as to encourage innovation and experimentation.

- Training courses are essential so that government employees charged with overseeing compliance with legislation on restoration become familiar with the overall objectives, concepts, definitions, and principles of restoration ecology.

\section{Acknowledgments}

We warmly thank P. Woodworth, A. Clewell, C. Fontaine, B. Merlot, K. Rodriguez, and R. Hobbs for comments and suggestions that helped to shape and improve this manuscript. We gratefully acknowledge the Brazilian Research Council (CNPq) for productivity grants to G.D., R.R.R., M.T, J.M.D.T., M.C.M.M., S.V.M., V.L.E., and L.M.B. 


\section{LITERATURE CITED}

Alexander, S., C. Nelson, J. Aronson, D. Lamb, D. Martinez, J. Harris, et al. Opportunities and challenges for ecological restoration within REDD+. Restoration Ecology. In press.

Aronson, J. 2010. What can and should be legalized in ecological restoration? Revista Árvore 34:451-454.

Aronson, J., S. J. Milton, and J. N. Blignaut, editors. 2007. Restoring natural capital: science, business and practice. Island Press, Washington, D.C.

Barbosa, J. M., K. C. Barbosa, A. Potomati, S. E. Martins, and L. M. Asperti. 2003. Recuperação florestal com espécies nativas no estado de São Paulo: pesquisas apontam mudanças necessárias. Florestar Estatístico 6:28-34.

Barbosa, L. M., F. C. Parajara, E. E. Teixeira, T. C. Barbosa, K. C. Barbosa, N. A. Santos Júnior, and J. M. Barbosa. 2009. Diagnóstico sobre produção de sementes e mudas de espécies florestais nativas do Estado de São Paulo. Informativo ABRATES 12:527.

Birch, J. C., A. C. Newton, C. A. Aquino, E. Cantarello, C. Echeverría, T. Kitzberger, I. Schiappacasse, and N. T. Garavito. 2010. Costeffectiveness of dryland forest restoration evaluated by spatial analysis of ecosystem services. Proceedings of the National Academy of Sciences of the United States of America 107:21925-21930.

Brancalion, P. H. S., R. R. Rodrigues, S. Gandolfi, P. Y. Kageyama, A. G. Nave, F. B. Gandara, L. M. Barbosa, and M. Tabarelli. 2010. Instrumentos legais podem contribuir para a restauração de florestas tropicais biodiversas. Revista Árvore 34:455-470.

Bullock, J., J. Aronson, J. M. Rey Benayas, R. Pywell, and A. Newton. Restoration of ecosystem services and biodiversity. Trends in Ecology and the Environment. In press.

Calmon, M., P. H. S. Brancalion, A. Paese, J. Aronson, P. Castro, S. Costa da Silva, and R. R. Rodrigues. 2011. Emerging threats and opportunities for biodiversity conservation and ecological restoration in the Atlantic Forest of Brazil. Restoration Ecology 19:154-158.

Castanho, G. G. 2009. Levantamento florístico-fitossociológico de duas áreas antigas de restauração florestal no Estado de São Paulo. Unpublished Ph.D. thesis. Universidade de São Paulo, Piracicaba, Brazil.

Chazdon, R. L. 2008. Beyond deforestation: restoring forests and ecosystem services on degraded lands. Science 320:1458-1460.

Clewell, A. F., and J. Aronson. 2006. Motivations for the restoration of ecosystems. Conservation Biology 20:420-428.

Clewell, A. F., and J. Aronson. 2007. Ecological restoration: Principles, values, and structure of an emerging profession. Island Press, Washington, D.C.

Durigan, G., V. L. Engel, J. M. Torezan, A. C. G. Melo, M. C. M. Marques, S. V. Martins, A. Reis, and F. R. Scarano. 2010. Normas jurídicas para a restauração ecológica: uma barreira a mais para dificultar o êxito das iniciativas? Revista Árvore 34:471-485.

Ehrenfeld, J. G. 2000. Defining the limits of restoration: the need for realistic goals. Restoration Ecology 8:2-9.

Herold, M., and M. Skutsch. 2011. Monitoring, reporting and verification for national REDD+ programmes: two proposals. Environmental Research Letters 6:1-10.

Hobbs, R. J. 2007. Setting effective and realistic restoration goals: key directions for research. Restoration Ecology 15:354-357.
Martins, R. B. 2011. Diagnóstico dos produtores de mudas florestais nativas do Estado de São Paulo. Programa Mata Ciliar, Secretaria de Meio Ambiente do Estado de São Paulo, São Paulo.

Mittermeier, R. A., P. R. Gil, M. Hoffmann, J. Pilgrim, J. Brooks, C. G. Miitermeier, J. Lamourux, and G. A. B. Fonseca. 2004. Hotspots revisited: Earth's biologically richest and most endangered terrestrial ecoregions. Cemex, Washington, D.C.

Neßhöver, C., J. Aronson, J. N. Blignaut, D. Lehr, A. Vakrou, and H. Wittmer. 2011. Investing in ecological infrastructure. Pages $401-448$ in P. ten Brink, editor. The economics of ecosystems and biodiversity in national and international policy making. Earthscan, London, U.K. and Washington, D.C.

Oliveira, R. E., A. M. Souza, C. L. Rodrigues, and M. L. Romero. 2008 Aspectos da recuperação e uso de florestas em propriedades e paisagens rurais no Estado de São Paulo. Pages 45-73 in Recuperação florestal: um olhar social. Secretaria do Meio Ambiente, Fundação para a Conservação e Produção Florestal do Estado de São Paulo, São Paulo, Brazil.

Rey Benayas, J. M., A. C. Newton, A. Diaz, and J. M. Bullock. 2009. Enhancement of biodiversity and ecosystem services by ecological restoration: a meta-analysis. Science 325:1121-1124.

Rodrigues, R. R., S. Gandolfi, A. G. Nave, J. Aronson, T. E. Barreto, C. Y. Vidal, and P. H. S. Brancalion. 2011. Large-scale ecological restoration of high-diversity tropical forests in SE Brazil. Forest Ecology and Management 261:1605-1613.

Ruiz-Jaen, M. C., and T. M. Aide. 2005. Restoration success: how is it been measured? Restoration Ecology 13:569-577.

SER (Society for Ecological Restoration). 2004. Society for Ecological Restoration International's primer of ecological restoration (available from http://www.ser.org/Primer)

Tabarelli, M., A. V. Aguiar, M. C. Ribeiro, J. P. Metzger, and C. A. Peres. 2010. Prospects for biodiversity conservation in the Atlantic Forest: lessons from aging human-modified landscapes. Biological Conservation 143: $2328-2340$

Yin, R., and G. Yin. 2009. China's Ecological Restoration Programs: initiation, implementation and challenges. Pages 1-19 in R. Yin, editor. An integrated assessment of China's ecological restoration programs. Springer, New York.

\section{Supporting Information}

Additional Supporting Information may be found in the online version of this article:

Appendix S1. São Paulo State Resolution on Forest Restoration.

Appendix S2. Brazilian Resolution on the Recuperation of Permanent Preservation Areas.

Appendix S3. "Forest Remnants Program" of the São Paulo State Policy on Climate Change.

Please note: Wiley-Blackwell is not responsible for the content or functionality of any supporting materials supplied by the authors. Any queries (other than missing material) should be directed to the corresponding author for the article. 